\title{
Spontaneous Closure of a Full-Thickness Macular Hole Associated with Proliferative Diabetic Retinopathy and Persistent Vitreomacular Traction
}

\author{
Benjamin J. Reinherz ${ }^{a} \quad$ Jeffrey S. Rubin ${ }^{b}$ \\ ${ }^{a}$ St. Johns Episcopal Hospital, and ${ }^{b}$ New York Eye and Ear Infirmary of Mount Sinai School \\ of Medicine, New York, N.Y., USA
}

\section{Key Words}

Spontaneous closure $\cdot$ Macular hole $\cdot$ Diabetic retinopathy $\cdot$ Vitreomacular traction

\begin{abstract}
Diabetic retinopathy worsens the prognosis of macular holes compared to those of idiopathic etiology. While spontaneous closure of idiopathic macular holes is a well-documented phenomenon, spontaneous closure of macular holes associated with proliferative diabetic retinopathy is rare. We report a case of spontaneous closure of a macular hole associated with proliferative diabetic retinopathy and persistent vitreomacular traction.
\end{abstract}

\section{(c) 2016 The Author(s)}

Published by S. Karger AG, Basel

\section{Introduction}

Spontaneous closure of idiopathic full-thickness macular holes (FTMH) is a welldocumented observation [1]. According to several authors, total posterior vitreous detachment is the suggested catalyst that precipitates this occurrence [1,2]. Diabetic retinopathy worsens the prognosis of FTMH compared to that of an idiopathic etiology [3]. We report a case of a 28-year-old male with proliferative diabetic retinopathy (PDR) and vitreomacular traction (VMT) who developed a FTMH 2 weeks following an intravitreal bevacizumab injec-

\section{KARGER}


tion. The patient had spontaneous closure of the macular hole within several weeks despite persistence of the VMT.

\section{Case Report}

A 28-year-old male with PDR, fibrovascular proliferation, and macular edema in both eyes complained of sudden-onset blurred vision in his left eye (OS). The patient had been treated over a 2-year period with focal and scatter laser photocoagulation as well as intravitreal bevacizumab therapy to treat both the proliferative retinopathy and macular edema. Two weeks prior to the onset of his new symptoms, the patient had a best corrected visual acuity (BCVA) of 20/40 OS and a new mild vitreous hemorrhage due to PDR in his left eye which was treated with an intravitreal bevacizumab injection. Examination on the day of the patient's new symptoms revealed a BCVA of 20/50 OS. Spectral domain optical coherence tomography (OCT, Spectralis, Heidelberg Engineering, Heidelberg, Germany) showed a taut anterior-posterior nasal vitreomacular membrane and an adjacent FTMH, measuring 363 $\mu \mathrm{m}$ at its base (fig. 1). The patient was started on topical bromfenac $0.9 \%$ OS every $12 \mathrm{~h}$ (b.i.d.) for adjunctive retinal edema management. Eight weeks later, the patient's BCVA improved to 20/30 OS and OCT examination revealed spontaneous closure of the macular hole and persistent VMT in the nasal macula (fig. 1). The macular hole continues to remain closed 9 months following spontaneous closure.

\section{Discussion}

While the mechanism of FTMH formation associated with PDR is not well understood due to the complexity and infrequency of these holes [3], the rate of spontaneous closure of such entities has yet to be clearly elucidated. The incidence of spontaneous idiopathic macular hole closure was reported to occur in $11.5 \%$ of patients, all of whom had a posterior vitreous detachment [1]. However, patients with diabetic retinopathy were excluded from that study. Spontaneous macular hole closure in patients with coexisting diabetic retinopathy has been reported in two cases. Lee et al. [3] reported a case of a 72-year-old female with PDR and spontaneous closure of a FTMH in the presence of a complete posterior vitreous detachment. The authors attributed the spontaneous closure to the coexisting posterior vitreous detachment. Errera et al. [4] reported the spontaneous closure of a FTMH and persistent VMT in an 81-year-old patient with non-proliferative diabetic retinopathy treated with laser photocoagulation 5 years prior. Their hypothesis was that laser photocoagulation induced retinal pigment epithelial cell activation and subsequent Mueller cell nuclear migration contributed to the spontaneous macular hole closure [4].

The pathophysiological impetus for macular hole formation associated with diabetic retinopathy may be due to either VMT or retinal edema [5]. Gandorfer et al. [5] demonstrated that the premacular cortical vitreous is thickened due to the proliferation of fibroblasts and fibrous astrocytes along native vitreous collagen in $77 \%$ of patients with diabetic macular edema. The authors further demonstrated single or multilayered cellular membranes developing along native collagen, leading to tangential VMT. According to Steel and Lotery [2], VMT occurs in 24-32\% of eyes with diabetic macular edema. Brazitikos and Stangos [6] postulate that intraretinal exudation may lead to retinal atrophy and intraretinal cyst formation. The horizontal orientation of the Mueller cell processes and anatomically thin retinal tissue 
Reinherz and Rubin: Spontaneous Closure of a Full-Thickness Macular Hole Associated with Proliferative Diabetic Retinopathy and Persistent Vitreomacular Traction

in the fovea, in conjunction with increasing pressure from the intraretinal exudation, predisposes the fovea to macular hole formation secondary to diabetic retinopathy $[6,7]$.

It is unclear whether the intravitreal bevacizumab injection 2 weeks prior to the onset of symptoms played a role in our case. A single case of FTMH developing 2 weeks following bevacizumab therapy has been reported and attributed to contraction of the posterior hyaloid and the fibrovascular membrane [8]. Our case differs in that there is a focal area of nasal anterior to posterior VMT that remained unchanged prior to development of the macular hole and after its spontaneous closure. The role of the VMT as a cause is also questionable since the traction was present nasal to the macular hole, and FTMHs associated with VMT typically form at the point of traction [2]. We can hypothesize that a temporary disturbance in the vitreous dynamics immediately following the injection led to a transient increase in the VMT resulting in macular hole formation. This theory may also explain the spontaneous closure, since there was no change in anterior to posterior traction before the macular hole developed or after it closed.

Kurz and Kurz [9] reported a single case of spontaneous closure of a FTMH treated with topical ketorolac. While complete posterior vitreous detachment was present in this case, the authors state that macular hole closure was potentiated by pharmacologically induced resolution of the macular edema [9]. Because our patient had a previous history of retinal edema, we elected to treat our patient with topical bromfenac $0.9 \%$ b.i.d.

In summary, we report a case of a FTMH associated with PDR, VMT and edema that occurred 2 weeks following an intravitreal bevacizumab injection. The patient was treated with topical bromfenac and observation. The macular hole closed within several weeks resulting in improvement in vision.

\section{Statement of Ethics}

The authors have no ethical conflicts to disclose.

\section{Disclosure Statement}

The authors have no financial interests to disclose relevant to this work. This work has not been presented previously.

\section{References}

1 Ezra E, Gregor ZJ; the Moorfields Macular Hole Study Group: Surgery for idiopathic full-thickness macular hole two-year results of a randomized clinical trial comparing natural history, vitrectomy, and vitrectomy plus autologous serum: Moorfields Macular Hole Study Group Report No. 1. Arch Ophthalmol 2004;122:224-236.

-2 Steel DHW, Lotery AJ: Idiopathic vitreomacular traction and macular hole: a comprehensive review of pathophysiology, diagnosis, and treatment. Eye 2013;27(suppl 1):S1-S21.

-3 Lee SN, Park KH, Song SJ: Spontaneous resolution of a full-thickness macular hole in proliferative diabetic retinopathy. Jpn J Ophthalmol 2008;52:342-343.

-4 Errera MH, Wickham L, Keane PA, Bird AC, Ezra E: Spontaneous macular hole closure without posterior vitreous detachment in a patient previously treated for diabetic maculopathy. Acta Ophthalmol 2013;91:e156-e157.

5 Gandorfer A, Rohleder M, Grosselfinger S, Haritoglou C, Ulbig M, Kampik A: Epiretinal pathology of diffuse diabetic macular edema associated with vitreomacular traction. Am J Ophthalmol 2005;139:638-652. 
Case Reports in

Ophthalmology

\begin{tabular}{l|l}
\hline Case Rep Ophthalmol 2016;7:163-166 \\
\hline DOI: 10.1159/000444657 & $\begin{array}{l}\text { ○ 2016 The Author(s). Published by S. Karger AG, Basel } \\
\text { www.karger.com/cop }\end{array}$ \\
\hline
\end{tabular}

Reinherz and Rubin: Spontaneous Closure of a Full-Thickness Macular Hole Associated with Proliferative Diabetic Retinopathy and Persistent Vitreomacular Traction

6 Brazitikos PD, Stangos NT: Macular hole formation in diabetic retinopathy: the role of coexisting macular edema. Doc Ophthalmol 1999;97:273-278.

7 Gass JD: Reappraisal of biomicroscopic classification of stages of development of a macular hole. Am J Ophthalmol 1995;119:752-759.

8 Mitamura Y, Ogata K, Oshitari T, Asaumi N, Yamaoto S: Retinal detachment with macular hole following intravitreal bevacizumab in patient with severe proliferative diabetic retinopathy. Br J Ophthalmol 2008;92:717-718.

9 Kurz PA, Kurz DE: Macular hole closure and visual improvement with topical nonsteroidal treatment. Arch Ophthalmol 2009;127:1687-1688.

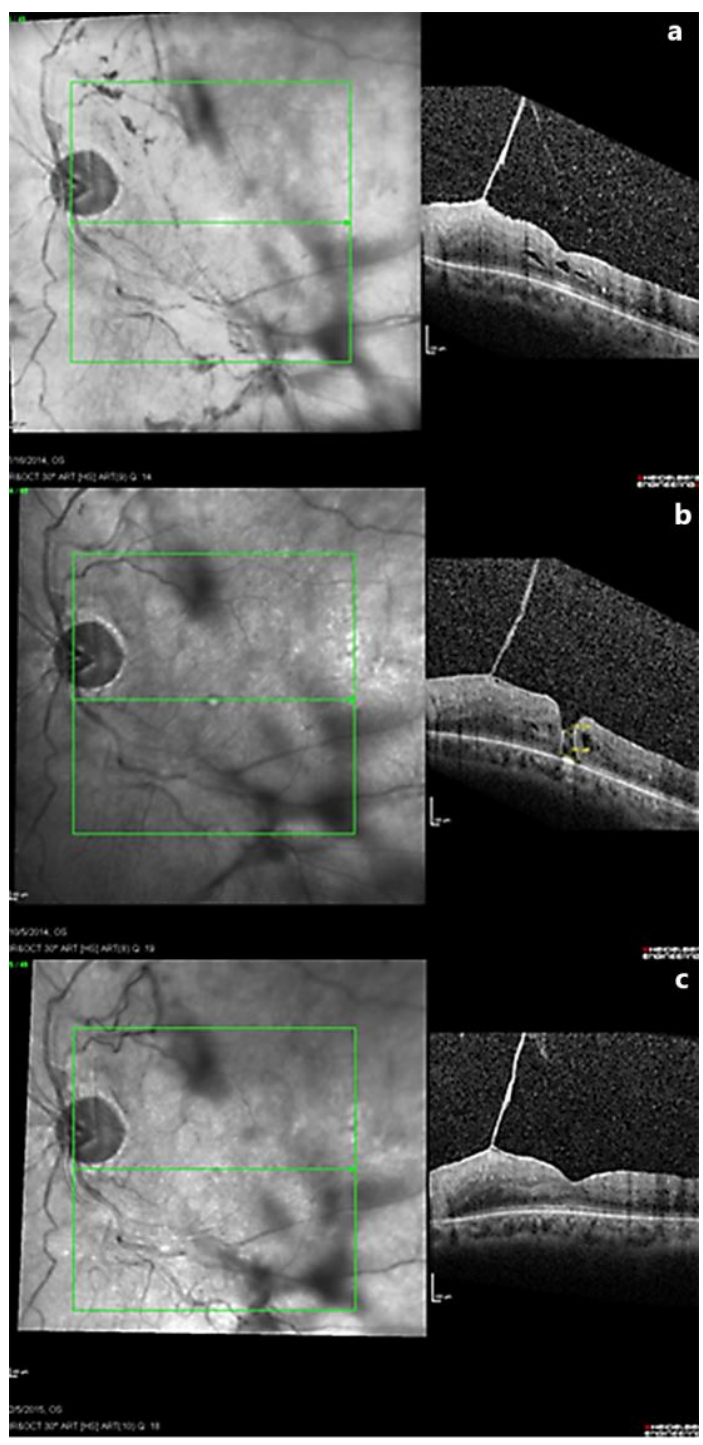

Fig. 1. OCT and corresponding scanning laser ophthalmoscopy images OS of initial intraretinal exudate and VMT (a), subsequent FTMH formation (b), and spontaneous macular hole closure with persistent $\operatorname{VMT}(\mathbf{c})$. 